\title{
The University as a Site for Transformation around Sustainability
}

Winter, J., Cotton, D., Grant, V. and Hopkinson, P. (2015) The University as a Site for Transformation around Sustainability. International Journal of Innovation and Sustainable Development. Volume 9. No 3-4. pp 303-320

DOI:10.1504/IJISD.2015.071857

Keywords Transformative learning, Education for Sustainable Development, pedagogy, informal learning.

\begin{abstract}
Education for Sustainable Development (ESD) has emerged in response to the negative consequences of economic and industrial processes. These issues are highly complex and their mitigation suggests social and economic transformation underpinned by a paradigm shift in favour of sustainability. Higher Education (HE) plays a crucial role in ESD; however there is little research which has investigated the links between transformative learning theories and ESD. This paper reports on research which explored academic and student perceptions of opportunities for transformation around sustainability in two UK universities. The findings suggest that, despite shared understanding about the nature of pedagogic approaches that promote deep learning, academics are wary about promoting transformation beyond the professional sphere and students are more likely to have transformative experiences outside the formal curriculum. There are indications that universities have potential as sites for transformation around sustainability but, at present, this potential is not achieved.
\end{abstract}

\section{Introduction}

Education for Sustainable Development (ESD) has emerged in response to scientific, political and social concerns over negative consequences of economic growth and industrial processes. Current models of production and consumption have failed to internalise environmental impacts and the development of a 'world economy' has resulted in sharp contrasts in social and economic wellbeing within and beyond the nation state. These issues are highly complex and their mitigation strongly suggests social and economic transformation underpinned by a paradigm shift in favour of sustainability. Education, at all levels, has long been considered a vital part of these reforms (Sterling, 2001).

ESD originated in the 1970 s as a techno-rationalist approach to mitigating sustainability issue which prioritises a simple linear cause and effect models for reaching solutions, with little thought for linked issues). Such approaches advocate information provision as a way to foster pro-environmental and pro-sustainable behaviour change, an approach which has increasingly been found wanting (Sterling 2001). Despite a growing scientific consensus around the impeding impacts of climate change, peak oil and associated sustainability issues, individuals, organisations and industry have resisted changes which impact on their lifestyles, culture and prosperity (Harich, 2010): Information provision has not resulted in the 
desired behaviour change. Greater understanding of the cultural implications of sustainability has led educators to explore and foster interpretivist and sociallycritical ESD (Robottom and Hart, 1993). Advocates of these approaches posit that ESD must be constructivist, critical and contextual and argue that to promote transformation - seen as the 'holy grail' of behaviour change (Jackson, 2005) - it must facilitate a critical evaluation of values and promote action competency (Breiting, 2000). 'Graduates of higher education should 'know something about sustainability, have the skills to act sustainably if they wish to and they should have the personal and emotional attributes that require them to behave sustainably' (Shepherd, 2008 p90).

The focus on personal and emotional attributes makes ESD stand apart from traditional disciplinary contexts where the emphasis is on content and skills or professionalism (Biglan, 1973). Many ESD advocates argue that attitudes and values should also form part of the educational experience, a stance that is challenging for the HE sector which has traditionally objectified both learners and learning (Bekir and Wiley, 2007). Nonetheless, 'enormous potential exists for universities to be leaders in challenging the status quo, challenging paradigms and openly practicing new ways of living, teaching and learning' (Moore, 2005 p78). It can be argued that universities are ideal sites in which to present and debate the ideological struggles of society (Castells, 2001). Thus, there is increasing interest in the potential role of the university as a site for transformation around sustainability.

\section{Transformative Learning and Education for Sustainable Development}

There are a wide range of conceptualisations of transformative learning which emerge from psychology, philosophy and sociology. Here, we focus on transformative learning theory which largely originates from work in adult education settings (Cranton, 2006; Mezirow, 1978,1997, 2000; Taylor, 2007). Although over time the original work has evolved and split in focus between individual and social change, the core premise of the theory remains intact. It posits that individuals hold 'frames of reference', essentially world-views which are made up of 'habits of mind', (assumptions that are formed in childhood through cultural assimilation and socialisation). The resulting 'points of view', in which our sense of self and values are interwoven, are manifested in an external representation of self and mediated through attitude, beliefs, judgements and behaviours. Transformative learning is concerned with challenging these 'frames of reference' through a process of psychocritical interpretation and re-interpretation of experience (Taylor and Cranton, 2012). This involves construction of a new or revised interpretation, based on critical reflection and rational discourse, which enables individuals to challenge the validity of their former assumptions (see Mezirow, 1978, 1997, 2000; Taylor, 2007).

A number of authors have explored the distinctions between transformative and other forms of learning including Bateson (1972) and Kitchener (1983) who identify hierarchical levels of cognitive processing: cognition, meta-cognition and epistemic learning (Table 1). 
Table 1. Levels of learning

\begin{tabular}{|c|c|c|}
\hline Order of change/learning & Seeks/ leads to & Can be labelled as \\
\hline First order change & \multirow[t]{2}{*}{ Effectiveness / efficiency } & 'Doing things better' \\
\hline Cognition & & $\begin{array}{l}\text { Conformative/ } \\
\text { Transmissive }\end{array}$ \\
\hline Second order change & \multirow{2}{*}{$\begin{array}{l}\text { Examining and changing } \\
\text { assumptions }\end{array}$} & 'Doing better things' \\
\hline Meta-cognition & & Reformative/Transactional \\
\hline Third order change & \multirow[t]{2}{*}{ Paradigm change } & 'Seeing things differently' \\
\hline Epistemic learning & & Transformative \\
\hline
\end{tabular}

Adapted from Bateson (1972) and Sterling (2010-11)

Arguably, much of the education that takes place in universities is in the form of first and second order change (Sterling, 2012) and there are well-documented reasons for this. Transformative learning requires tutors to create an environment where learners can debate and reflect upon questions which challenge their 'frames of reference'. This requires students to feel comfortable in the setting and to trust the educator and their peers, since the process of transformative learning may be a deeply uncomfortable one (Moore, 2005). In addition, the learner must be willing and ready to engage emotionally in the process. There is a longstanding debate about the place of emotions in higher education, for example, Sagan (2008 p175) describes emotions as 'baggage' and Lucas (1999) as 'inappropriate territory'. However, others argue that 'good learning engages feelings' (Weiss, 2000 p21) and that tutors should support students' development of a 'critical emotional literacy' (Spendlove, 2007 p157) through affective learning practices and outcomes (Haigh, 2006). These contrasting views have led Moore (2005: 83) to argue that 'transformative learning is not for everyone and neither is it applicable to all fields of study'. Questions remain about the capacity of academics to facilitate transformative learning, about student readiness to participate, and about the appropriateness of transformative learning within the outcomes-based, rationalist model of education which is currently dominant in contemporary enterprise cultures in UK HE (Light et al.2009).

Despite these barriers there remains a vigorous interest in the conceptual congruence that appears to exist between ESD and transformative learning. Thomas (2009:246) calls ESD a 'developing example of transformative education', and Elliot (2010:96) suggests that 'The aims of [ESD] and transformative education are closely coupled particularly in the affective domain and ... sustainability in the curriculum can offer space for transformation to occur' (see also Moore, 2005; Sterling, 2010-11; Winter et al. 2012). There is, however, little empirical research which documents transformation in the HE sector: 'Interest in the coupling of ESD and transformative learning is evidently growing, however, there remains relatively little research that analyses already existing models of and strategies for embedding these into the curriculum' (Elliot, 2010:100). In part this is explained by the almost complete lack of 
dedicated transformative curricula outside of specialist centres such as Schumacher College in Devon (a small independently-run institution whose strapline is 'Transformative Learning for Sustainable Living') (Blake et al. 2013). However, there are hints that transformation may occur in HE despite the lack of purposive transformative programmes. For example, research by Cotton and Alcock (2012) indicates a correlation (when other factors are held constant) between participation in $\mathrm{HE}$ and higher levels of commitment to environmental sustainability. There is also some evidence from previous research that critical reflection may play a role in transforming perspectives and behaviour in HE (Winter and Cotton, 2012).

In light of these developments, this paper considers the potential for student transformation around sustainability in two UK universities. It draws on empirical research which aimed to investigate the experiences which students and academics associate with transformative learning about sustainability in $\mathrm{HE}$.

\section{Methodology}

The study sites were two universities, Plymouth and Bradford, which characterise most strongly successful whole-institution transformation in sustainability in the UK (Hopkinson et al. 2008; Jones et al. 2010). Despite both having a very strong record in sustainability, the two institutions differ in many other respects. Plymouth is a new (post-1992) university, and Bradford is an old university. They have very different student bodies with the Bradford student population (in line with its local population) being significantly more ethnically diverse. Plymouth is the highest overall performer in the UK's 'People and Planet' Green League (which ranks universities in terms of their sustainability). It hosts the Centre for Sustainable Futures, focusing on teaching and learning, an Institute for Sustainability Solutions Research, and an office of procurement and sustainability which focuses on campus greening. At Bradford there is a similar focus on cross-institutional transformation and integration of sustainability activities under the banner of the Ecoversity. Bradford has a strong record in sustainable student accommodation and a wide range of activities and awards (two national awards for Outstanding Contribution to Sustainable Development). The aim of the research was to investigate contexts where the opportunities for transformative learning around sustainability would arguably be greatest, thus the focus on institutions which have been successful in sustainability was a deliberate choice. However, it was also useful to study two contexts which were varied in order to compare and contrast a range of student and academics experiences.

Within each institution, the sample included students and academics from a range of disciplines (Geography, Business and Engineering, see Table 2). These subjects were selected as they include at least some formal curriculum content on sustainability but with differing approaches to sustainability. 25 undergraduate students from both universities accepted the invitation to participate in the project. Narrative accounts of sustainability-themed transformative learning experiences were gathered through semi-structured interviews using a critical incident approach (Tripp, 1993; Brookfield, 1987). Tripp (1993:8) suggests that "critical incidents are produced by the way we look at a situation: a critical incident is the interpretation of the significance of an event". Critical incidents can be either positive or negative they are simply events which are considered important by participants. The critical incident approach has been rarely used in sustainability research, yet it provides a 
simple and appropriate method for encouraging students to reflect on specific concrete experiences and can be useful when considering transformation because thinking and behaviour are often altered as a result of a critical experience. Students were asked questions to encourage them to recall specific incidents or events which had influenced or changed their perspective on sustainability.

1. What happened in the critical incident?

2. How has your thinking changed as a result of this event?

3. What do you do differently as a result of this event?

Academics were also invited to participate in the project by email. In total 17 academics from Geography, Business and Engineering attended a face to face interview which lasted on average for one hour (Table 2). The interviews were focused on three themes. i) Transformative learning, awareness and implementation of in their teaching work, (ii) ESD, awareness and implementation of in their teaching work and (iii) identifying and creating links between the two.

Table 2. Sample

\begin{tabular}{lllllll}
\hline & \multicolumn{2}{l}{ Geography } & Business & \multicolumn{2}{l}{ Engineering } \\
\hline & Student & $\begin{array}{l}\text { Acade } \\
\text { mics }\end{array}$ & Student & $\begin{array}{l}\text { Acade } \\
\text { mics }\end{array}$ & Student & $\begin{array}{l}\text { Acade } \\
\text { mics }\end{array}$ \\
Plymouth & 5 & 4 & 5 & 4 & 2 & 1 \\
Bradford & 6 & 2 & 3 & 3 & 4 & 3 \\
\hline Total & 11 & 6 & 8 & 7 & 6 & 4 \\
\hline
\end{tabular}

Total student sample: 25 Total academics sample: 17

Analysis of the data was undertaken by three members of the project team to enhance reliability. Data were analysed using the constant comparative method to draw out cross-cutting themes (Silverman, 2005). This involved an iterative process of reading and re-reading data, looking for similarities and differences between accounts, and noting specific references to transformative learning and sustainability. The coding frame was developed through a process of negotiation between the researchers, enhancing inter-rater reliability and the robustness of the findings. Analysis involved consideration of the ways and extent to which students and academics were aware of transformative learning moments around sustainability; the extent to which these emerged as a result of their engagement within their specialist fields of study; and the potential for ESD to have transformative capacity beyond the disciplinary context. NVivo software was used as an aid to analysis, and to enhance the ability to sort data by respondents' institution, discipline and personal characteristics. The degree of generalisation which can be made from this kind of research is limited. Clearly this sample does not enable statistical generalisation, however, the data collected can be used to theorise about the wider applicability of the findings on transformative learning and sustainability using 'theoretical inference' (Hammersley, 1998). 


\section{Findings}

\section{i) Academics}

All the academics interviewed considered sustainability to be relevant to their discipline and embedded sustainability into their teaching (Table 3); this was anticipated from the purposive sample that was utilised for this study.

\section{Table 3. Academics views on sustainability}

\begin{tabular}{l|ll}
\hline Question & No. agree & $\%$ agree \\
\hline $\begin{array}{l}\text { Do you have autonomy and } \\
\text { institutional support to explore and } \\
\text { embed sustainability in the curriculum? }\end{array}$ & 17 & $100 \%$ \\
\hline $\begin{array}{l}\text { Do you include explicit teaching of } \\
\text { sustainability in the current curriculum? }\end{array}$ & 17 & $100 \%$ \\
\hline $\begin{array}{l}\text { Do you have any plans for ongoing } \\
\text { curriculum development specifically } \\
\text { incorporating sustainability? }\end{array}$ & 14 & $82 \%$ \\
\hline
\end{tabular}

There was also evidence that sustainability was considered relevant within the selected disciplines beyond the individuals sampled, as well as being an important institutional agenda in these institutions:

'At that time in the business school there was a considerable amount of teaching and learning about sustainability across the board, not in every module and a lot of it wasn't actually described as such, it was just there" (PU3).

'Everything that we do has the focus of sustainability in some shape or form, but some is more explicit than others' (UOB7).

'It's actually something we have...embedded very greatly throughout the whole of the curriculum (PU5).

Academics were able to identify the pedagogic approaches they deemed most useful in teaching and learning around sustainability (Table 4). For the most part these aligned with what have been termed 'sustainability pedagogies' because of their potential to foster deep, meaningful learning in authentic contexts through social, experiential and constructivist learning environments (Cotton and Winter, 2010). These are also aligned with more generic recommendations about good pedagogic practice: 'Sustainability pedagogy is simply good pedagogy' (HEFCE, 2008 p35). 
Table 4. Academic and student perspectives on engaging pedagogy for sustainability

\begin{tabular}{|c|c|c|c|}
\hline $\begin{array}{l}\text { Pedagogic } \\
\text { process }\end{array}$ & $\begin{array}{l}\text { \% Academic } \\
\text { (N) } \\
\text { Total } N=17\end{array}$ & $\begin{array}{l}\text { \% students (N) } \\
\text { Total } \mathrm{N}=25\end{array}$ & Examples from data \\
\hline $\begin{array}{l}\text { Critical thinking } \\
\text { and reflection }\end{array}$ & $76 \%(13)$ & $76 \%(19)$ & $\begin{array}{l}\text { Reflective diaries, reflective } \\
\text { discussion, reflecting on } \\
\text { the process of research. } \\
\text { Reflecting on learning has } \\
\text { potential to enhance } \\
\text { confidence and self-worth. }\end{array}$ \\
\hline Fieldwork & $58 \%(10)$ & $88 \% \%^{*}(14)$ & $\begin{array}{l}\text { Fieldwork promotes new } \\
\text { forms of understanding but } \\
\text { also social opportunities } \\
\text { between academics and } \\
\text { students which lead to } \\
\text { increased dialogue and } \\
\text { trust around sustainability } \\
\text { and learning. }\end{array}$ \\
\hline Placements & $47 \%{ }^{*}(8)$ & $72 \% \%^{*}(13)$ & $\begin{array}{l}\text { Working in professional } \\
\text { settings offers challenging } \\
\text { authentic opportunities to } \\
\text { implement action and take } \\
\text { professional responsibility; } \\
\text { this potentially leads to } \\
\text { increased understanding } \\
\text { about implementing } \\
\text { sustainability in practice. }\end{array}$ \\
\hline $\begin{array}{l}\text { Academics and } \\
\text { peer feedback }\end{array}$ & $47 \%(8)$ & $52 \%(13)$ & $\begin{array}{l}\text { Developing communication } \\
\text { and clarifying ideas about } \\
\text { sustainability }\end{array}$ \\
\hline $\begin{array}{l}\text { Independent } \\
\text { learning including } \\
\text { dissertation }\end{array}$ & $88 \%(15)$ & $56 \%(14)$ & $\begin{array}{l}\text { Undertaking research on } \\
\text { sustainability themed } \\
\text { subjects promoted } \\
\text { ownership, knowledge } \\
\text { construction and testing of } \\
\text { sustainability ideas. }\end{array}$ \\
\hline $\begin{array}{l}\text { Collaborative } \\
\text { learning } \\
\text { processes }\end{array}$ & $52 \%(9)$ & $52 \%(13)$ & $\begin{array}{l}\text { Group-work, research } \\
\text { informed discussions, } \\
\text { peer-learning, problem - } \\
\text { based learning based on } \\
\text { generating sustainability } \\
\text { solutions. }\end{array}$ \\
\hline
\end{tabular}

( ${ }^{*}$ Of those who reported experience of that pedagogy) 
Despite widespread understanding of pedagogic innovation and sustainability issues, there was very little awareness of transformative learning theory or its links to sustainability. When asked about transformative learning, academics held differing understandings, ranging from lack of awareness of the term:

'I was going to ask you to tell me what it means, I have no idea' (UOB3).

'I have certainly heard of the concept but I am not sure I have any clear sort of definitions except the changing from superficial to deep learning' (PU9).

To more informed responses:

'The big transformations, the more profound revisions of your way of thinking, where something really shifts and you look at the world anew and that particular framework of thinking has been challenged'(UOB4).

'I guess the idea is to try to encourage students to think about what they are doing and maybe they would make some changes in their lives as a result of the learning process that they had gone through' (PU3).

'A process where what you thought before you think differently. Where you've interpreted something in a way that you might not have interpreted it before, where you may have had an emotional response, an affective response to something that you might not have had before" (UOB1).

It should be noted that the latter responses were not well represented in the data and only two individuals claimed any prior knowledge of transformative learning theory itself.

This lack of knowledge about transformative learning theory did not prevent academics discussing the ways they facilitated students' disciplinary and professional transformation into geographers, engineers and business facilitators, however:

'Students will definitely change the way they perceive the world, and how they perceive what they're doing. Their whole outlook will change just by going on a placement ... It's having the experience and then going and doing it that makes the value of it. I think there are lots of moments like that. I mean, the placement is a big one which is identifiable for those particular ones, and there's such a tangible result change, a totally different outlook' (UOB4).

'Developing independent learning, developing a sense of professionalism and understanding what is right and what is wrong so ethics, moral position and stance and ethics is really important' (PU1).

'Because they are coming out different from the way they came in and one would hope that it's introducing lifelong. I think it's transformative in terms of skill set, knowledge but also the broader understanding of issues' (PU8).

'In Management that's the first time they have ever been challenged on what their role in society is. And I think that's definitely a transformative aspect of their learning' (PU7). 
However, it was clear that academics were both uncertain and uncomfortable about changing students' perspectives on sustainability beyond the professional domain which they considered highly controversial. There were no reported explicit attempts to transform students towards more sustainable attitudes or behaviours; rather transformation may emerge indirectly as a result of engagement with the discipline. Any suggestion that they might explicitly aim to transform students' attitudes was greeted with concerns about influence and indoctrination:

'You have to be very careful and I see my role as ... definitely not one of coercion or influence even but raising awareness... we are in an academic free thinking supportive environment here so it's not about telling people how you think it should be... but just to present the facts as objectively as I can... and they decide for themselves.' (PU1).

'I suppose the distinction I am really trying to make is we would not be in any way assessing or indeed engaging whether in the end the students either changed their behaviour or values in any way ... whether in any way it had transformed their behaviour is something which you wouldn't necessarily know or gauge and I suppose also to some extent probably we would say that is not the point (PU5).

'We wouldn't even necessarily know what views individuals held [about sustainability] and also... my feeling would also be that my role is not to attempt as it were to force this type of transformation, it's more to say well this is the understanding, this is why this is important, this is why it should be considered rather than to say you must consider it you must do this' (PU5).

It is notable that academics use value-laden words like 'force' or 'coerce' to express their fears about engaging with potentially controversial issues in the curriculum. Despite institutional and individual enthusiasm for sustainability and its embedding as a core element of the curriculum in these three disciplines, transformative learning is not explicitly utilised by academics. They expressed strong concerns about potential bias and persuasion, revealing a clear tension within a HE context which prioritises autonomy, objectivity and criticality. Any sense of critique regarding underpinning assumptions about the discipline as an ideologically neutral educational space was notably absent.

\section{ii) Students}

Students, like academics, were not immediately familiar with the concept of transformative learning and had not generally considered their university life as a context for transformation. However, they were familiar with sustainability: In total 20 $(80 \%)$ of the students confirmed that they had been taught sustainability content on their course. Eleven (44\%) students reported value and behavioural changes around sustainability with fourteen (56\%) reporting none. Of those who did report changes, only one reported a significant 'high impact' critical incident, with the majority reporting that changes resulted from an ongoing process of exposure to knowledge, experience and social interactions which accumulated to inform a change in perspective. Importantly these were not always in response to formal educational experiences but were related to the holistic university experience. 
Students reported that subject content and professional requirements were significant in developing their knowledge about sustainability. This differed according to discipline but several students made links between sustainability content and developing identity as a professional in that area:

'It is our duty as designers to look into sustainability and the environmental impact of that, and if we don't do that, who is going to? ... We design objects and products that go through their product life and then they're returned into manufacturing, separated into materials and reused instead of being thrown away and discarded' (UOBS1).

'Definitely ...I guess...it's changed the way I thought about it, I now try and act sustainably ... because we're told how important it is. I think it's impossible to go to geography here and not come away more sustainable than you went in' (UPS1).

However, one implication of student transformation in the disciplinary context was that this could be limited to the professional domain and there was less evidence that students' personal perspectives were challenged:

'I will definitely take some of the skills from my student life and put them into my work life and maybe my personal life but it (formal education) has changed me more as a student than as an actual person' (UOBS4).

This is an interesting insight into the distinctions made between different learning domains, and underlines the difficulty in engaging in education which involves the whole person in transformation.

In line with academics, students reported certain pedagogies as more engaging and appropriate for learning about sustainability (Table 4). In addition, some students also identified belonging to professional bodies, attending conferences and participating in enterprise competitions as relevant; however, it may be that as unusual events they were simply more memorable. There was evidence that students found experiences which transcended the formal curriculum to have additional impact on transformation around sustainability. In particular students discussed the importance of internationalisation, independent living, social relationships and extra-curricular activities. Internationalised students called upon contrasting experiences of sustainability in industry, governance and environmental contexts and culture and reflected on why these differences occurred, highlighting the complexity of inter-cultural understanding:

'In different cultures and different countries sustainability will mean different things to different people because the challenges are going to be different' (PUS5).

Importantly, it was not just cognitive understanding that was strengthened by internationalisation; there were examples of affective outcomes of these experiences:

'From an educational perspective l've changed because l've seen more, I've learnt more. I went to Africa so, I mean, l've seen a lot of poverty and I've 
seen people that aren't as well off as me and people don't have the chance to come here ... that's definitely transformed me as a person' (UPS1).

In terms of the wider student experience, participants reported that informal aspects of moving to university such as living independently, budgeting, managing social situations and getting involved in new activities and communities were part of an intense cultural shift which contributed to personal development and perspective change. Students talked passionately about the people they met at university which they described as a melting pot of cultures, ideas and alternative ways of thinking and behaving. Intense social relationships with peers could prompt self-reflection:

'So if you spend time with someone, you live with someone, you will inherently adapt parts of their culture. I've met a vast number of people from different backgrounds and you meet them and adapt. So if you see something that they do as being better and you like it then you think it's a good idea (UOBS2).

Some of these changes were associated with sustainability, for example, taking responsibility for paying for food and services, resource use and waste disposal often promoted individual and collaborative reflection on how resources were consumed or disposed of:

'I feel around the university I don't think you can just throw an empty bottle on the ground, because everyone around me is aware of what we stand for [sustainability] and that it is just going to look so primitive' (UOBS11).

In particular students highlight the move from halls of residence to shared private housing as a catalyst for exploring the logistical and ethical dimensions of environmentally significant behaviours.

Meeting people was often associated with social groups, $19(76 \%)$ of the students belonged to extra-curricular societies and clubs including hill walking, archery, scuba diving, running, swimming, cycling and boxing. Both new relationships and new activities could act as prompts to reflection on sustainability:

'I met a friend through archery club and he made me think, "Actually, there's more to life" so, really, it was his influence because he's a very outdoorsy person and that's where he gets his buzz, so, he sort of opened my mind to it. The more time you spend on the moors you think, "Actually, this is really quite impressive and I wouldn't want to destroy it' (UPS7).

Membership of these groups often resulted in students exploring and spending time in the natural environment, experiences which many students reported as significant in increasing value for environment and conservation.

Other students participated in Student Union activities, for example environmental clean-ups and rubbish collection, or volunteered with local organisations. Students identified these experiences with developing leadership skills and increased responsibility and awareness for health and wellbeing: 
'I think the university has taught me to be a lot more open minded about things [sustainability]. I volunteer with Leeds City Council doing ecological surveys on bats, waterfalls and amphibians' (UOB S8)

The sorts of behavioural change that students reported as a result of changed perspectives on sustainability included using online rather than paper resources, printing double sided pages, recycling, seeking out information about recycling, energy conservation, car share and reducing car use for short journeys, purchasing 'ethical' and 'green' products, vegetarianism and boycotting companies with track records in unsustainable practice. Despite the lack of explicit efforts from academics towards transformation, the sense from students was that this 'just happened' - the experience of participating in higher education was transformative, and such transformation might (but need not) encompass sustainability:

'I would certainly say I am a different person now to the person who came in that first day; yes I would definitely say that, there would be something wrong I think if it weren't the case' (UOBS12).

The data from students therefore suggests that whilst there is a shared understanding with academics about key educational experiences around sustainability, many of the most powerful learning contexts for transformation in this domain are exhibited outside the formal curriculum and largely 'ad hoc' events.

\section{Discussion}

This research raises some interesting questions about the potential for the university to act as a site for transformation around sustainability. If we consider the findings against Bateson's (1972) levels of learning outlined earlier then the data suggest some limited evidence of third order learning (a profound re-ordering of character, indicative of a paradigm change of underpinning values and observable changes to behaviour) in students' professional identities as a result of exposure to the formal curriculum. In addition, nearly half of the student participants reported perspective change around sustainability, whereby they examined and revised their assumptions (in line with second order change) with some reporting behavioural modification as a result of this process. Sterling (2010-11) identifies second order change as a precursor to engagement in third order, and both as sophisticated levels of cognition critical to developing a normalised sustainability literate populace. Arguably then, there is merit in exploring and encouraging the environmental and social characteristics associated with second order change to increase the numbers of students who are practised and skilled at challenging their own assumptions and are then at least conceptually and cognitively open to the possibility of third order change.

In terms of the context for transformative learning in the university, it is clear that there are both possibilities and problems with the formal curriculum as a site for transformation. Whilst there were many positive examples of sustainability within the curriculum (and encouragingly awareness of sustainability pedagogies was relatively high), scope for transformation beyond the professional sphere was limited. Where sustainability and professional practice were seen as being in alignment there was less tension around engaging students in transformation, indicating the importance of professional bodies as drivers for such change. With increasing pressure from professional bodies to include ESD in the curriculum, there may be more scope for 
academics to explore and experiment with pedagogies that encourage second and third order change. However, the limits to this transformation should be noted: Students in this research clearly struggled to make links between their professional and personal commitments to sustainability; only a minority were experiencing perspective change that engaged their 'emotional and intuitive selves' (Sterling, 2004), their core and terminal values.

There is scope for further enhancing the links between different disciplines and sustainability, as well as for encouraging embedding of active and experiential pedagogies, especially sustainability themed work-placements. The potential for transformation may be increased by the growing focus on internationalisation in $\mathrm{HE}$, as evidenced here by the key role of international fieldwork (noting, however, the obvious conflicts with carbon reduction aspirations). But also through approaches which encourage inter-cultural collaboration and there is a useful 'internationalisation at home' literature that can be readily drawn on by educators interested in this area (HEA 2014: Wachter 2003). The findings should, however, be contextualised within the wider social-cultural milieu. Despite on-going policy support for ESD and the relevance of transformative action to this agenda, the academics in this study were cautious about their involvement in 'transforming' students beyond the remit of professional practice. It is clear that transformative learning sits uneasily with the outcomes-based, individualistic educational model which is widespread in HE, and our findings suggest significant wariness in the mainstream academy. Whilst is could be argued that there are opportunities for critiquing the current $\mathrm{HE}$ ethos through "refusal to endorse the university as 'a factory' for the knowledge economy" (Blewitt, 2013), our research shows little evidence of the economic model being subject to serious questioning from within the academy.

An ongoing barrier to development of transformative learning in the curriculum is caused by the widespread concerns about persuasion, propagandism and indoctrination which echo those raised in previous research (e.g. Cotton, 2006). These fears, whilst understandable, reflect a flawed view of the educational endeavour which can never be value-free, and they continue to act as a conservative force on transformation within the curriculum. As Apple (1996) argues: "There is ... always a politics of official knowledge, a politics that embodies conflict over what some regard as simply neutral descriptions of the world and what others regard as elite conceptions that empower some groups whilst disempowering others." (Apple, 1996 p23). Moreover, the evidence presented here suggests that students who did report perspective change were responding through their own informed choice to a complex mosaic of stimuli of which the formal curriculum was only one part. Indeed even within the literature on transformative learning there is the recognition that there can be no pre-conceived outcome by the educator, they can only facilitate the process and transformation in whatever guise may occur. There may well then be an argument for academics to consider these wider environments which are conducive to facilitating perspective change as vehicles by which to enhance sustainability education.

Outside the curriculum, transformative experiences were also reported, and this provided a less contentious context for personal transformation. Unfamiliar environments and social relationships were often the decisive motivators for perspective change. Both prompted evaluation and reflection on previous assumptions and required emotional investment to become familiar and comfortable 
with the new habitus. The act of attending university exposed students to many novel environments and forced them to create new social networks; identification with different groups of people stimulated reflection on identity and values to reconcile tensions and build common associations (Tajfel and Turner, 1979; 1986). However, a potential barrier to this context as a mode of transformation for sustainability was simply its ad hoc nature: in the social domain there was no guarantee that students were exposed or attracted to individuals or activities that would stimulate reevaluation of sustainability perspectives. Where this did occur, however, students reported that these events were powerful experiences with wider impact on their values and behaviours. It may be that some exposure to inspirational speakers in the formal curriculum, or designing learning activities that bridge the links between professional and personal experience, would offer the potential to tap into these valuable extra-curricular and informal experiences which underpin much higher order change. This echoes the views of sustainability educators such as Sterling (2010-11) who suggests that transformation occurs spontaneously as a result of social learning, and adds strength to arguments about the benefits of linking the formal and informal curricula (Hopkinson et al. 2008; Winter et al. 2012).

These findings also prompt a wider discussion framed by Janet Moore's (2005) paper, 'Is Higher Education ready for Transformative Learning?' Sterling (2004:56) presents transformative education as one involving 'the whole person, and affects change in deep levels of values and beliefs through a process of re-perception and re-cognition. It is not then a matter of intellectual and conceptual learning, but learning that engages our emotional and intuitive selves as well'. That academics were not explicitly engaging in this process is unsurprising and echoes the findings of previous research, both in schools and HE which suggests that tutors are wary of promoting positive attitudes or behaviours with respect to sustainability (Cotton et al. 2007; Environmental Audit Committee, 2005). There were no explicit transformative education programmes in either institution so perhaps it is unsurprising that there was little evidence of third order change - even in these leading edge institutions. However, the social, cultural and educational characteristics of university life appear to be facilitative of second order change with potential glimpses of third. The university, as a site of socialisation, may enhance the 'readiness' of students (Moore, 2005) for transformation, creating prepared minds (Barnett, 1990) that are open to the potential risks and discomfort associated with perspective change around sustainability. The remaining challenge is to increase the opportunities students have to experience higher level transformation that links the personal and professional spheres to develop epistemic learning for sustainability.

\section{Conclusions}

This research aimed to investigate the kinds of educational experiences which students and academics associate with transformative learning about sustainability. The findings suggest that transformative learning for sustainability in higher education is problematic, being viewed by academics as controversial, and by students as rare - and often occurring outside the formal curriculum through significant social relationships or events. Where the impact of the formal curriculum is seen more clearly, however, is at the interface of professional and personal experiences. For academics, the only generally agreed 'acceptable' form of 
transformation is through the discipline or professional sphere: however, the impact of these changes may be limited to this sphere alone, thus reducing the potential impact on wider life experiences, attitudes or behaviours.

Despite the apparent tensions, many students do experience some kind of perspective change during their time at university. Both students and academics agree on the kinds of formal educational experiences that increase opportunities for sustainability perspective change interactive, experiential, real-world pedagogies. Frequently, however, transformative experiences did not take place in response to a purposefully designed programme but instead emerged through a range of events located in different points in space and time over the course of the students' time at university. Academics were aware of, but not party to, the informal dimensions of student life which in many cases promoted perspective change around sustainability. Failure to integrate the informal with the formal curriculum may therefore reduce opportunities for transformation. The findings imply that if perspective change is considered to be an important pursuit for ESD in HE then greater attention should be paid to the whole student experience, recognising that the underpinning characteristics of perspective change involve context, significant social relationships and linking professional and personal experiences.

\section{References}

\section{References}

Apple, M. W. (1996) Cultural Politics and Education (Buckingham, UK: Open University Press).

Bateson, G. (1972) Steps to an Ecology of Mind. San Francisco: Chandler.

Barnett, R. (1990) The Idea of Higher Education. Society for Research into Higher Education: London

Bekir S. G. \&. Wiley, D, A. (2007). Instructional Technology and Objectification. Canadian Journal of Learning and Technology. Volume 33(3). Available online http://www.cjlt.ca/index.php/cj|t/article/view/159/151

Biglan, A., (1973) The characteristics of subject matter in academic areas, Journal of Applied Psychology, 57, 195-203

Blake, J., Sterling, S., and Goodson, I. (2013) Transformative Learning for a Sustainable Future: An Exploration of Pedagogies for Change at an Alternative College. Sustainability 5 (12), 5347-5372

Blewitt, J. (2013) EfS: contesting the market model of higher education. In The Sustainable University. London: Routledge. 51-70

Breiting, S. (2000). Sustainable development, environmental education and action competence. Critical Environmental and Health Education: Research Issues and Challenges. B. Jensen, Schnack, K. and Simovska, V. Copenhagen, The Danish University of Education.151-165 
Brookfield, S. (1987) Developing Critical Thinkers, OU press. Buckingham.

Castells, M. (2001) "Universities as dynamic systems of contradictory functions" in J. Muller et. al. (eds) Challenges of globalisation. South African debates with Manuel Castells, Cape Town: Maskew Miller Longman. 206-223.

Cotton, D.R.E. (2006) Implementing curriculum guidance on environmental education: the importance of teachers' beliefs. Journal of Curriculum Studies 38 (1): 67-83.

Cotton, D.R.E and Alcock, I. (2012) Commitment to environmental sustainability in the UK student population. Studies in Higher Education 38 (10):1457-1471

Cotton, D.R.E, Warren, M.F., Maiboroda, O. \& Bailey, I. (2007) Sustainable Development, Higher Education and Pedagogy: A study of lecturers' beliefs and attitudes. Environmental Education Research 13 (5): 579-597

Cotton, D.R.E \& Winter J (2010) 'It's not just bits of paper and light bulbs: sustainability pedagogies' in Jones P; Selby D; Sterling S (ed.) Sustainability Education Earthscan / James \& James pp 39 - 54

Cranton, P (2006) 2nd Ed, Understanding and Promoting Transformative Learning, A guide for Educators of Adults, San Francisco, Jossey-Bass Publishers.

Environmental Audit Committee (2005) Environmental Audit Fifth Report. http://www.publications.parliament.uk/pa/cm200405/cmselect/cmenvaud/84/8402.ht $\mathrm{m}$

Elliot, J. (2010-11) Insights to transformative learning through education for sustainable development. Learning and Teaching in Higher Education. Issue 5. Pp96-113

Haigh, M. (2006) Deep Ecology Education: Learning from its Vaisnava Roots. Canadian Journal of Environmental Education (CJEE), Vol 11, No 1 - 2006. 43-56. http://cjee.lakeheadu.ca/index.php/cjee/article/viewFile/503/400

Hammersley, M. (1998) Reading Ethnographic Research: A Critical Guide, Longman, London.

Harich, J. (2010) Change Resistance as the Crux of the Environmental Sustainability Problem", System Dynamics Review, Available online http://www.thwink.org/sustain/articles/009/ChangeResistanceAsCrux.htm

HEA (2014) Internationalising the Curriculum. Available online https://www.heacademy.ac.uk/sites/default/files/resources/Internationalising_the_cur riculum.pdf

Hopkinson, P., Hughes, P. and Layer, G. (2008) "Sustainable graduates: linking formal, informal and campus curricula to embed education for sustainable development in the student learning experience". Environmental Education Research Vol 14. No 4. pp 435-454. 
Higher Education Funding Council for England (HEFCE) (2008) Strategic review of sustainable development in higher education in England. Available online from: www.hefce.ac.uk/pubs/rdreports/2008/rd03_08/ (accessed 6 March 2009).

Jackson, T. (2005). Motivating Sustainable Consumption. Guildford, Sustainable Development Research Network (Briefing One).

Jones, P., Selby, D. and Sterling, S. (2010) Sustainability education: Perspectives and practice across Higher Education. Earthscan: London

Kitchener, K, S. (1983) Cognition, Metacognition, and Epistemic Cognition. A ThreeLevel Model of Cognitive Processing. Human Development, v26 n4 p222-32 Jul-Aug 1983

Light, G., Cox, R. and Calkins, S. (2009) Learning and Teaching in Higher Education: The Reflective Professional. London. Sage.

Lucas, B. (1999) With brains in mind, Times Higher Education Supplement, 9 July 1999, pp.29-30.

Mezirow, J. (1978) Perspective Transformation. Adult Education, pp. 100-110.

Mezirow, J. (1997) "Transformative learning: Theory to practice". New Directions for Adult and Continuing Education, Vol 74, pp 5-12.

Mezirow, J. (2000). Learning as transformation: critical perspectives on a theory in progress. Jossey Bass: San Francisco.

Moore, J. (2005) Is Higher Education Ready for Transformative Learning? A Question Explored in the Study of Sustainability. Journal of Transformative Education, Vol.3, No.1, pp 76-91.

Robottom, I. and Hart, P. (1993) Research in Environmental Education: Engaging the Debate. The Deakin-Griffith Environmental Education Project. Deakin University

Sagan, O. (2008) Playgrounds, studios and hiding places: emotional exchange in creative learning spaces, Art, Design \& Communication in Higher Education, vol.6, no.3, pp.173-186.

Shepperd, K. (2008) Higher Education for sustainability: Seeking affective learning outcomes. International Journal of Sustainability in Higher Education. Vol. 9. No.1 pp68-86

Silverman, D. (2005) Doing Qualitative Research, 2nd ed, Sage, London.

Spendlove, D. (2007) A conceptualisation of emotion within art and design education: a creative, learning and product-orientated triadic schema, International Journal of Art \& Design Education, vol.26, no.2, pp.155-166.

Sterling, S. 2012. The future fit framework - an introductory guide to teaching and learning for sustainability in HE. York: Higher Education Academy. 
Sterling, S. (2001). Sustainable Education: Revisioning Learning and Change. Totnes, Green Books Ltd.

Sterling, S. (2004) Linking Thinking: Report for the WWF. Available from. http://www.eauc.org.uk/wwf linking thinking new perspectives on thinking

Sterling, S. (2010-11) Transformative learning in sustainability: sketching the conceptual ground. Learning and Teaching in Higher Education Vol. 5: pp17-33.

Tajfel, H. and Turner, J, C. (1979). An integrative theory of inter-group conflict. Austin. W. G. and Worchel, S. The Social Psychology of Inter-group Relations. Brooks/Cole. Monterey, CA . pp 33-47.

Tajfel, H. and Turner, J, C. (1986). The social identity theory of inter-group behaviour. Worchel, S. and Austin, L, W Psychology of Inter-group Relations. Nelson-Hall. Chicago, pp 27-40

Taylor, E. (2007) "An update of transformative learning theory: a critical review of the empirical research" (1999-2005), International Journal of Lifelong Education, Vol 26 No 2: pp173-191.

Taylor, E. \& Cranton, P. ( 2012) The Handbook of Transformative Learning: Theory, Research, and Practice. Jon Wiley and Sons: San Francisco

Thomas, I. (2009) "Problem-Based Learning in Universities: Critical Thinking, Transformative Learning, Sustainable Education and Problem based learning in universities". Journal of Transformative Education Vol 7, No 3,pp 245-264

Tripp, D. (1993) Critical Incidents in Teaching, Routledge: London and New York.

Wächter, B. (2003) An Introduction: Internationalisation at Home in Context. Journal of Studies in International Education 7:5, 5-11.)

Weiss, R. (2000) Brain -Based Learning. Training and Development. July 2000 pp 20-24

Winter J \& Cotton D (2012) 'Making the hidden curriculum visible: sustainability literacy in higher education' Environmental Education Research. 18 (6), pp 783 796

Winter J, Cotton D \& Grant V (2012) 'Experiencing transformation: A student Perspective' Sustainable Development at Universities: New Horizons Frankfurt: Peter Lang pp $85-97$ 